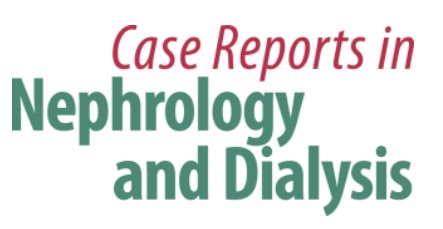

Case Rep Nephrol Dial 2018;8:246-252

DOI: $10.1159 / 000494715$

Published online: November 21, 2018

(C) 2018 The Author(s)

Published by S. Karger AG, Basel

www.karger.com/cnd

This article is licensed under the Creative Commons Attribution-NonCommercial 4.0 International License (CC BY-NC) (http://www.karger.com/Services/OpenAccessLicense). Usage and distribution for commercial purposes requires written permission.

\title{
A Case of Self-Limiting Crescentic Immunoglobulin A Glomerulonephritis Associated with Sternoclavicular Arthritis
}

\author{
Yoko Fujita $^{a}$ Tomo Suzuki $^{a}$ Wei Han ${ }^{a}$ Shiika Watanabe \\ Koichi Yahagi ${ }^{a}$ Mayumi Nakata $^{a}$ Takeshi Okamoto $^{a}$ Daisuke Ichikawa ${ }^{a}$ \\ Junki Koike $^{b}$ Yugo Shibagaki ${ }^{a}$ \\ ${ }^{a}$ Division of Nephrology and Hypertension, Department of Internal Medicine, St. Marianna \\ University School of Medicine, Kanagawa, Japan; 'Department of Diagnostic Pathology, \\ St. Marianna University School of Medicine, Kanagawa, Japan
}

\section{Keywords}

IgA glomerulonephritis · Sternoclavicular arthritis · Spontaneous remission

\begin{abstract}
Immunoglobulin (Ig) A glomerulonephritis (GN) is a heterogeneous disease affected by various factors. Genetic and other factors "hit" DNA, causing IgA malformation and ultimately glomerular injury. We describe a rare case of crescentic IgA GN with sternoclavicular (SC) arthritis in a 75-year-old woman. Despite active IgA GN with cellular crescents, the patient achieved remission of IgA GN without glucocorticoid therapy after remission of SC arthritis was achieved. Considering the patient's clinical course, this case suggested a relationship between IgA GN and SC arthritis.




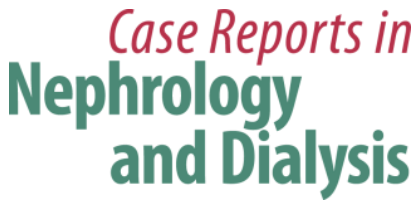

Case Rep Nephrol Dial 2018;8:246-252

DOI: $10.1159 / 000494715$

(c) 2018 The Author(s). Published by S. Karger AG, Basel www.karger.com/cnd

Fujita et al.: A Case of Self-Limiting Crescentic Immunoglobulin A Glomerulonephritis Associated with Sternoclavicular Arthritis

\section{Introduction}

Immunoglobulin (Ig) A glomerulonephritis (GN) is the most common type of glomerulonephritis worldwide [1]. The pathogenesis of IgA GN has not been fully clarified; however, it has been reported that several factors, such as genetic factors, mucosal infection, and antigen stimulation, are related to its pathogenesis. These factors cause structural abnormalities of IgA that accumulate and deposit in glomerular mesangial areas [2]. The multi-hit hypothesis explains a theory for the pathogenesis of IgA GN, in that these several aforementioned factors "hit" DNA and lead to glomerular injury [1]. Thus, IgA GN is considered a heterogeneous disease.

The causes of sternoclavicular (SC) arthritis vary and include autoimmune disorders and infection [3]. Among them, the synovitis, acne, pustulosis, hyperostosis, and osteitis (SAPHO) syndrome is the most common. Kidney disease with SC arthritis is rare [4].

Here, we describe a case of IgA GN with SC arthritis. Despite active IgA GN with cellular crescents, the patient achieved remission of IgA GN without glucocorticoid therapy after remission of SC arthritis. Therefore, we considered that IgA GN in this case may have been associated with SC arthritis.

\section{Case Report}

A 75-year-old woman presented to the Rheumatology Department of our hospital with a chief complaint of pain in the sternum, which had continued for 3 years. She occasionally took nonsteroidal anti-inflammatory drugs (NSAIDs) for her pain. SC arthritis was suspected, and she continued taking NSAIDs. In the next year, she was diagnosed as having seronegative SC arthritis based on magnetic resonance imaging (MRI) findings of a high-intensity signal located in the lower edge of the right SC joint (Fig. 1). Results of the urine examination indicated no abnormality. Human leukocyte antigen (HLA) typing was positive for A9, A11, A24, B5, B51, and B67 and negative for B27. No typing was performed for HLA-DQ or QR. We did not know the cause of SC arthritis because HLA typing was negative for HLA-B27. The rheumatologist started oral treatment with salazosulfapyridine because the patient did not have an acute infection. The pain was relieved with salazosulfapyridine treatment; however, she could not continue this treatment for more than 3 months because of an allergic reaction. Thus, NSAIDs were restarted (Fig. 2), and they successfully controlled her pain.

Five months after she was diagnosed as having seronegative SC arthritis, the laboratory data revealed a serum creatinine $(\mathrm{Cr})$ level of $0.77 \mathrm{mg} / \mathrm{dL}$, and urinalysis showed nephritic sediment with acutely increasing significant occult blood and proteinuria. She started to have swollen legs and foaming of the urine. Therefore, she was referred to our division, the Nephrology Department, for further investigation of the acute progression of proteinuria and glomerular hematuria. She ceased taking NSAIDs.

She had a medical history of hypertension, hyperlipidemia, diabetes mellitus, ectopic pregnancy, cataracts, glaucoma, ptosis, and tonsillitis. The physical examination revealed no rash, palmoplantar pustulosis, bilateral leg edema, or pain in the shoulders and SC joints. Her tonsils were not obviously enlarged.

Laboratory studies showed a white cell count of 8,200/ $\mu \mathrm{L}, \mathrm{C}$-reactive protein level of 0.03 $\mathrm{mg} / \mathrm{dL}$, hemoglobin level of $11.8 \mathrm{~g} / \mathrm{dL}$, serum $\mathrm{Cr}$ level of $0.64 \mathrm{mg} / \mathrm{dL}$, and estimated glomerular filtration rate of $68.7 \mathrm{~mL} / \mathrm{min} / 1.73 \mathrm{~m}^{2}$. Urinalysis revealed 2+ proteinuria, a spot urine protein level of $3.1 \mathrm{~g} / \mathrm{g} \mathrm{Cr}$, urinary albumin-to-protein ratio of $82.1 \%$, and no abnormal 


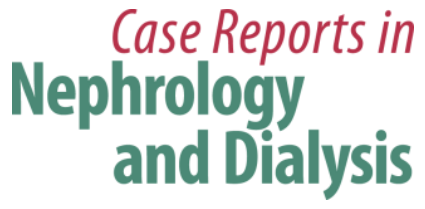

Case Rep Nephrol Dial 2018;8:246-252

DOI: $10.1159 / 000494715$

(c) 2018 The Author(s). Published by S. Karger AG, Basel www.karger.com/cnd

Fujita et al.: A Case of Self-Limiting Crescentic Immunoglobulin A Glomerulonephritis Associated with Sternoclavicular Arthritis

urinary protein fraction including $\mathrm{M}$ protein. No abnormality was found in the level of tubular proteins, such as $\mathrm{N}$-acetyl- $\beta$-D-glucosaminidase, $\alpha_{1}$-microglobulin, and $\beta_{2}$-microglobulin. Urinalysis also revealed $3+$ occult blood with dysmorphic red blood cells. The serological examination revealed an IgA level of $361 \mathrm{mg} / \mathrm{dL}$, and C3 and C4 levels were not decreased. Myeloperoxidase-antineutrophil cytoplasmic antibodies (ANCA) and proteinase 3-ANCA were not detected. We performed a kidney biopsy. The kidney biopsy specimen contained 23 glomeruli: 3 globally sclerotic glomeruli, 15 glomeruli with an enlarged mesangial area, and 5 glomeruli with mild diffuse mesangial proliferation that had cellular crescents (3), a fibrocellular crescent (1), and segmental endocapillary proliferation (1). Tubular atrophy and interstitial fibrosis was accompanied with a mild to moderate level of inflammatory cell infiltration. The immunofluorescent examination revealed deposition of IgA and C3 in the mesangial area and along the capillary walls, and there was no difference in deposition between $\kappa$-light and $\lambda$-light chains. Electron microscopy showed inconspicuous electron-dense deposits and no hump. We diagnosed the patient as having IgA GN with cellular crescents. The MEST score, which represents histologic components included in the Oxford classification of IgA GN, was M0E1S0T1C1 [5]. In addition, the biopsy specimen was negative for the nephritis-associated plasmin receptor (NAPlr) and plasmin activity (Fig. 3).

Since this was a highly active case of IgA GN, steroid pulse therapy was considered, but we did not administer it because she had diabetes mellitus, glaucoma, a medical history of hepatic virus B, and was elderly. After we started treatment with an angiotensin-converting enzyme, the patient's urinary protein level started to decrease, and it reached $0.18 \mathrm{~g} / \mathrm{g} \mathrm{Cr}$ within 22 months, although the level of serum Cr kept increasing up to $1.0 \mathrm{mg} / \mathrm{dL}$. Two years after the kidney biopsy, the number of red blood cells in the urine started to decrease without any treatment changes, while the levels of urinary protein and serum $\mathrm{Cr}$ remained at $0.17 \mathrm{~g} / \mathrm{g}$ $\mathrm{Cr}$ and $1.0 \mathrm{mg} / \mathrm{dL}$, respectively. Two years and 4 months after the biopsy, MRI still showed the high-intensity area located on the upper edge of the right SC joint, so methotrexate (MTX) was started. The number of red blood cells in the urine continued to decrease with improvement of the serum $\mathrm{Cr}$ level, which reached $0.8 \mathrm{mg} / \mathrm{dL}$, and improvement of the estimated glomerular filtration rate, which reached about $60 \mathrm{~mL} / \mathrm{min} / 1.73 \mathrm{~m}^{2}$, although the level of spot urine protein increased to $0.56 \mathrm{~g} / \mathrm{g}$ Cr. Three years after the biopsy, she started to have a continuous cough with an increased liver enzyme level. Soon after MTX was stopped, the liver enzyme levels also decreased. The number of red blood cells in the urine almost disappeared, and the serum $\mathrm{Cr}$ level remained stable during these clinical events. The spot urine protein level decreased afterward. Four months after stopping MTX, the MRI findings disappeared, and another 4 months later, the serum $\mathrm{Cr}$ level reached $0.13 \mathrm{~g} / \mathrm{g} \mathrm{Cr}$, which met the criterion of clinical remission (less than $0.3 \mathrm{~g} / \mathrm{g} \mathrm{Cr}$ ) [6], and it continued to meet this criterion.

\section{Discussion}

The crescent formation in IgA GN is a poor prognostic factor [7]. Tumlin et al. [8] reported that methylprednisolone and intravenous cyclophosphamide were effective for crescentic, proliferative IgA GN. However, in our patient, we observed improvement of crescentic IgA GN without intensive treatment. Self-limiting IgA GN has been reported in children [9]. Furthermore, spontaneous remission has been reported even in IgA GN adult patients with nephrotic syndrome [10]. Thus, IgA GN has various histological manifestations and clinical courses.

We suspected that secondary IgA GN was related to SC arthritis based on our patient's clinical course. Secondary IgA GN is caused by multiple diseases, such as viral hepatitis, 


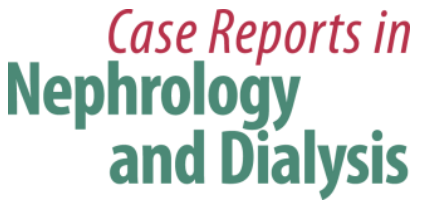

Case Rep Nephrol Dial 2018;8:246-252

DOI: 10.1159/000494715

(c) 2018 The Author(s). Published by S. Karger AG, Basel www.karger.com/cnd

Fujita et al.: A Case of Self-Limiting Crescentic Immunoglobulin A Glomerulonephritis Associated with Sternoclavicular Arthritis

Crohn's disease, ulcerative colitis, rheumatoid arthritis, infection, and malignant tumor [11]. As for inflammation, rheumatoid arthritis is one of the main causes of secondary IgA GN due to an autoimmune disorder, which causes IgA malformation [2,12]. SC arthritis is also a chronic inflammatory disease, and it could cause secondary IgA GN through the same mechanism.

A case of IgA GN complicated with SC arthritis is rare [4]. Recently, it was reported that SAPHO syndrome can be complicated by IgA GN with nephrotic syndrome. The bone lesions in patients with SAPHO syndrome were more frequently (77.6\%) located in the anterior chest than in any other part of the body [13]. We need to discuss whether SC arthritis in our patient was one of the symptoms of SAPHO syndrome or caused by other causes, such as infectious osteitis and tumoral conditions of the bone. For SAPHO syndrome, MRI may show inflammation around the lesion, accompanied with osteomyelitis. Herein, MRI showed that the lesion was limited to the right lower edge of the right SC joint without any inflammation around it. Considering this feature, we think that SAPHO syndrome was less likely the cause in our case.

As for infection, SC arthritis is especially associated with an infection from causative organisms, such as Staphylococcus aureus [5, 14]. SC arthritis may cause secondary IgA GN under the existence of a pathogen that "hits" galactose-deficient IgA1 involved in the pathogenesis of IgA GN [1]. Staphylococcus infection-associated GN resembles IgA GN [15]. To distinguish between IgA GN and Staphylococcus infection-associated GN, it is effective to detect the hump in electron microscopy and to measure the serum ANCA level [16]. In the present case, bacteremia was not suspected clinically, so we did not perform a blood culture. Local infection was ruled out based on computed tomography and MRI findings, which showed no abscess. The possibility of focal infection was speculated, but there was no correlation between the size of the tonsils and the clinical course of renal dysfunction in this case. We could not observe the serum ANCA level and hump in electron microscopy. Additionally, the staining result of NAPlr was negative. If the staining results of NAPlr and plasmin are positive, this suggests infectionrelated GN [17]. Herein, we could not indicate an association between IgA GN and infection. Thus, we could not determine whether SC arthritis was caused by Staphylococcus infectionassociated GN, so the causative agent of SC arthritis and IgA GN remains unknown.

In conclusion, the present case suggested a relationship between IgA GN and SC arthritis because active IgA GN improved without steroid or other immunosuppressant as SC arthritis improved.

\section{Acknowledgements}

The authors wish to acknowledge Dr. Takashi Oda, Development of Nephrology, Tokyo Medical University, for his technical help with nephritis-associated plasmin receptor and plasmin activity staining of the biopsy specimen.

\section{Statement of Ethics}

This article does not contain any studies with human participants or animals performed by any of the authors. Informed consent was obtained from the patient to publish her case. 


\section{Case Reports in Nephrology and Dialysis}

Fujita et al.: A Case of Self-Limiting Crescentic Immunoglobulin A Glomerulonephritis Associated with Sternoclavicular Arthritis

\section{Disclosure Statement}

The authors have no conflicts of interest to declare.

\section{Funding Sources}

The authors received no funding for this study.

\section{Author Contributions}

Y.F. and T.S. wrote the manuscript. T.O. and Y.S. were the patient's treating physicians. T.S., W.H., S.W., K.Y., M.N., D.I., and J.K. contributed histological interpretations. J.K. and Y.S contributed by reviewing and revising the manuscript.

\section{References}

1 Wyatt RJ, Julian BA. IgA nephropathy. N Engl J Med. 2013 Jun;368(25):2402-14

2 Suzuki Y, Suzuki H, Nakata J, Sato D, Kajiyama T, Watanabe T, et al. Pathological role of tonsillar B cells in IgA nephropathy. Clin Dev Immunol. 2011;2011:639074.

3 Govoni M, Colina M, Massara A, Trotta F. "SAPHO syndrome and infections”. Autoimmun Rev. 2009 Jan;8(3):256-9.

4 Morimoto K, Nakatani K, Asai O, Mondori K, Tomiwa K, Mondori T, et al. A case of synovitis, acne, pustulosis, hyperostosis, and osteitis (SAPHO) syndrome complicated by IgA nephropathy with nephrotic syndrome. CEN Case Rep. 2016 May;5(1):26-30.

5 Trimarchi H, Barratt J, Cattran DC, Cook HT, Coppo R, Haas M, et al.; IgAN Classification Working Group of the International IgA Nephropathy Network and the Renal Pathology Society; Conference Participants. Oxford Classification of IgA nephropathy 2016: an update from the IgA Nephropathy Classification Working Group. Kidney Int. 2017 May;91(5):1014-21.

6 Suzuki Y, Matsuzaki K, Suzuki H, Sakamoto N, Joh K, Kawamura T, et al. Proposal of remission criteria for IgA nephropathy. Clin Exp Nephrol. 2014 Jun;18(3):481-6.

7 Haas M, Verhave JC, Liu ZH, Alpers CE, Barratt J, Becker JU, et al. A multicenter study of the predictive value of crescents in IgA nephropathy. J Am Soc Nephrol. 2017 Feb;28(2):691-701.

8 Tumlin JA, Lohavichan V, Hennigar R. Crescentic, proliferative IgA nephropathy: clinical and histological response to methylprednisolone and intravenous cyclophosphamide. Nephrol Dial Transplant. 2003 Jul;18(7):1321-9.

9 Shima Y, Nakanishi K, Hama T, Mukaiyama H, Togawa H, Sako M, et al. Spontaneous remission in children with IgA nephropathy. Pediatr Nephrol. 2013 Jan;28(1):71-6.

10 Han SH, Kang EW, Park JK, Kie JH, Han DS, Kang SW. Spontaneous remission of nephrotic syndrome in patients with IgA nephropathy. Nephrol Dial Transplant. 2011 May;26(5):1570-5.

11 Pouria S, Barratt J. Secondary IgA nephropathy. Semin Nephrol. 2008 Jan;28(1):27-37.

12 Saha MK, Julian BA, Novak J, Rizk DV. Secondary IgA nephropathy. Kidney Int. 2018 Oct;94(4):674-81.

13 Okuno H, Watanuki M, Kuwahara Y, Sekiguchi A, Mori Y, Hitachi S, et al. Clinical features and radiological findings of 67 patients with SAPHO syndrome. Mod Rheumatol. 2018 Jul;28(4):703-08.

14 Ross JJ, Shamsuddin H. Sternoclavicular septic arthritis: review of 180 cases. Medicine (Baltimore). 2004 May;83(3):139-48.

15 Satoskar AA, Nadasdy G, Plaza JA, Sedmak D, Shidham G, Hebert L, et al. Staphylococcus infection-associated glomerulonephritis mimicking IgA nephropathy. Clin J Am Soc Nephrol. 2006 Nov;1(6):1179-86.

16 Nasr SH, D'Agati VD. IgA-dominant postinfectious glomerulonephritis: a new twist on an old disease. Nephron Clin Pract. 2011;119(1):c18-25.

17 Oda T, Yoshizawa N, Yamakami K, Sakurai Y, Takechi H, Yamamoto K, Oshima N, Kumagai H. The role of nephritis-associated plasmin receptor (NAPlr) in glomerulonephritis associated with streptococcal infection. J Biomed Biotechnol. 2012;2012:417675. 


\section{Case Reports in Nephrology and Dialysis}

Case Rep Nephrol Dial 2018;8:246-252

DOI: $10.1159 / 000494715$

c) 2018 The Author(s). Published by S. Karger AG, Basel www.karger.com/cnd

Fujita et al.: A Case of Self-Limiting Crescentic Immunoglobulin A Glomerulonephritis Associated with Sternoclavicular Arthritis
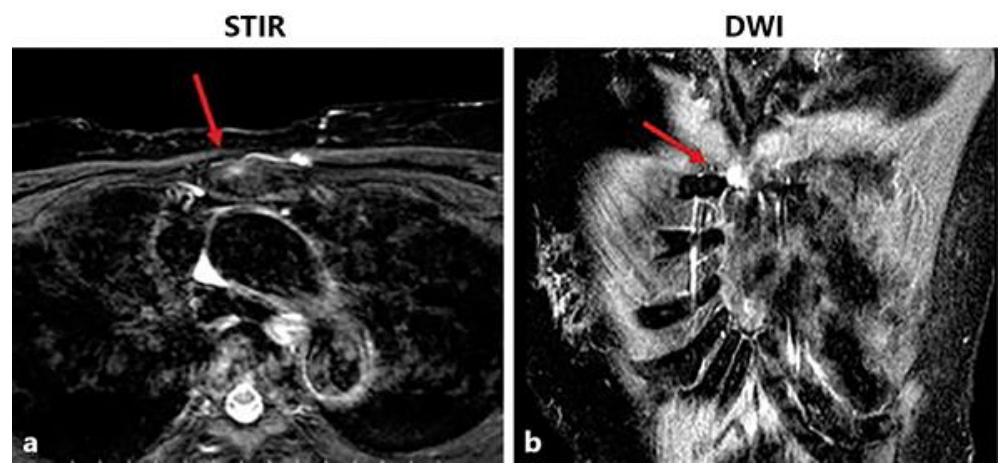

Fig. 1. Magnetic resonance imaging findings. The short-tau inversion recovery image (a) and diffusionweighted image (b) show a high-intensity area located on the lower edge of the right sternoclavicular joint (red arrow).

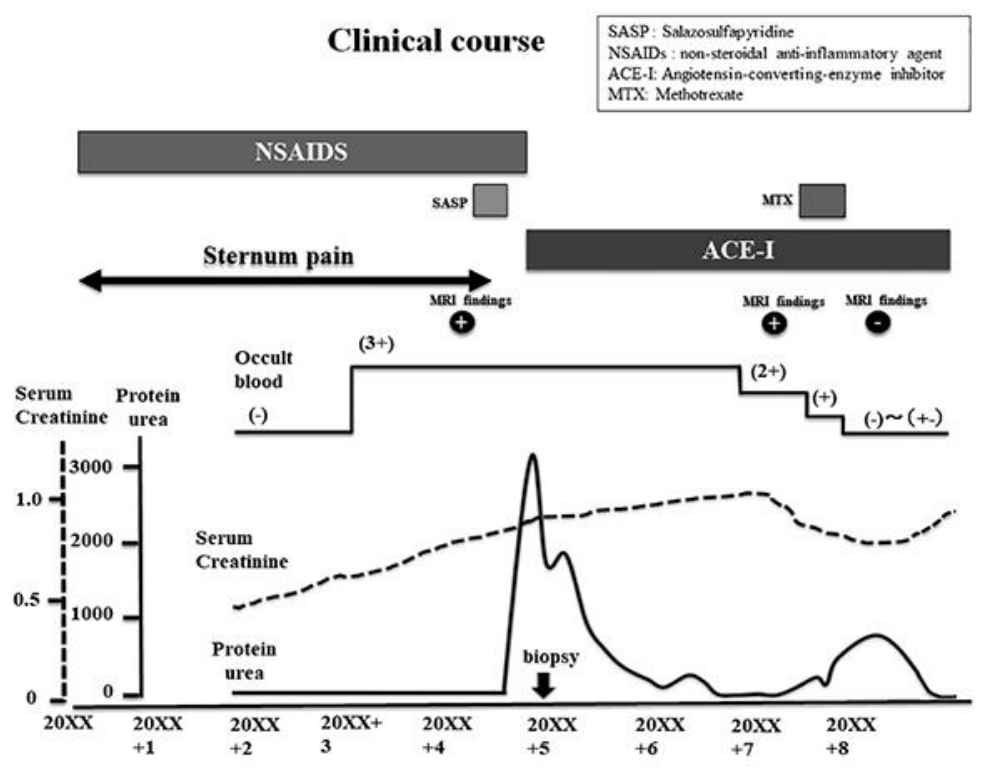

Fig. 2. Patient's clinical course. 


\section{Case Reports in Nephrology and Dialysis}

Case Rep Nephrol Dial 2018;8:246-252

DOI: $10.1159 / 000494715$

(c) 2018 The Author(s). Published by S. Karger AG, Basel www.karger.com/cnd

Fujita et al.: A Case of Self-Limiting Crescentic Immunoglobulin A Glomerulonephritis Associated with Sternoclavicular Arthritis

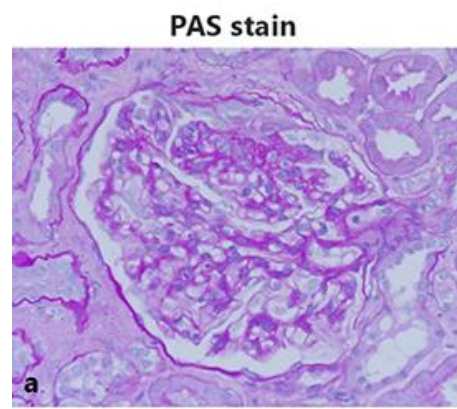

$\mathbf{k}$

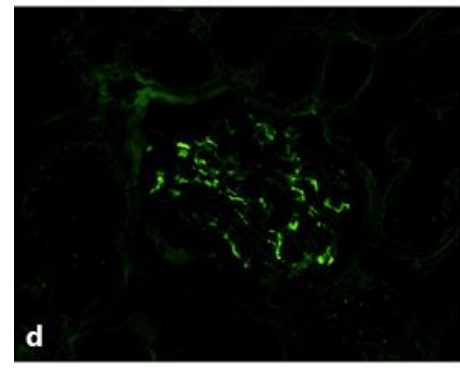

NAPIr-FITC $\lg A$

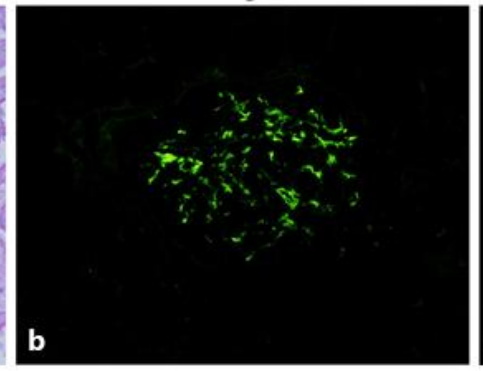

$\lambda$

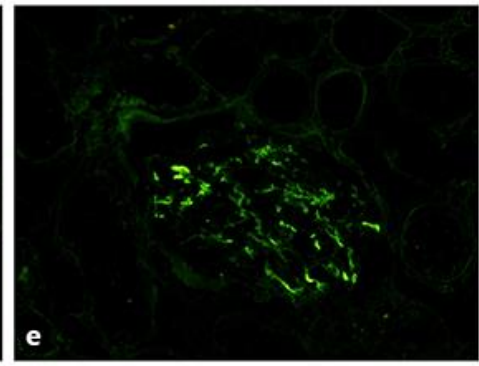

Plasmin
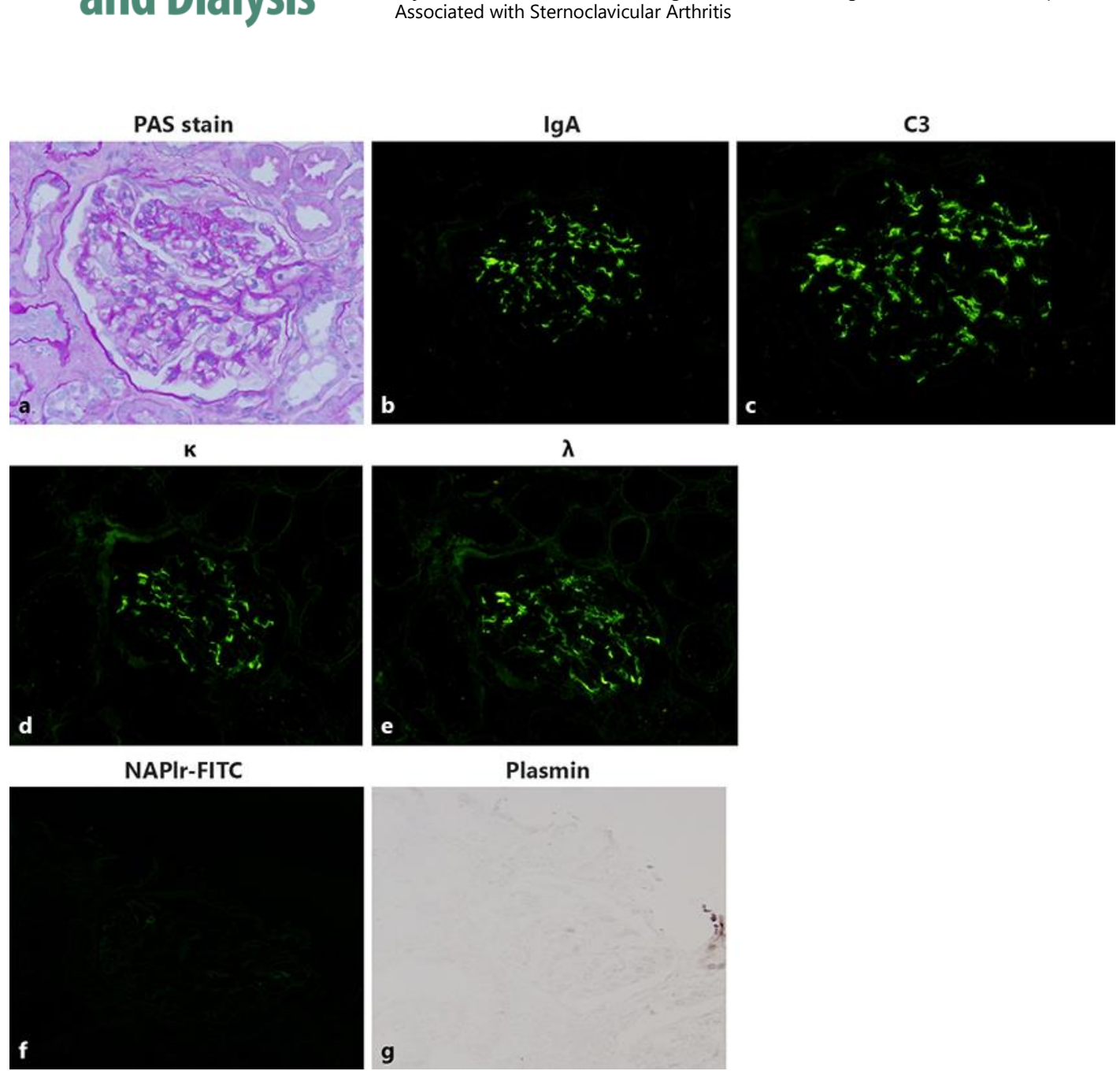

.
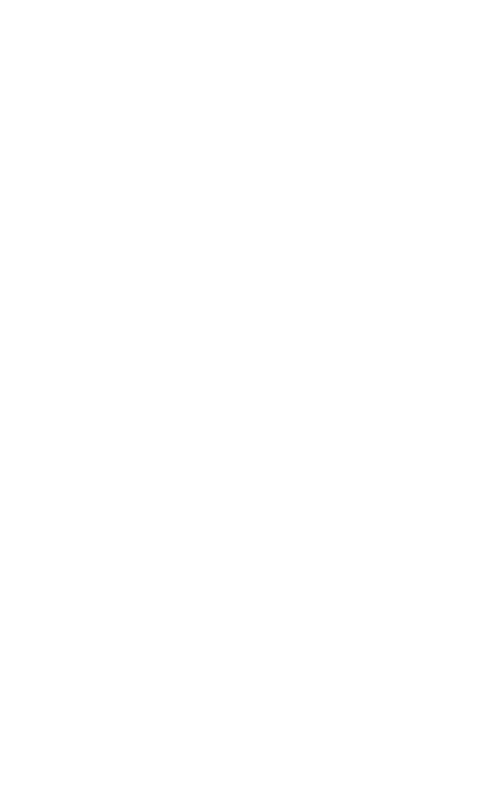

Fig. 3. Light microscopy shows a fibrocellular crescent with mild diffuse mesangial proliferative glomerulonephritis (a), and immunofluorescence microscopy shows immunoglobulin A (b) and mild positive C3 staining in the mesangial area (c), and no abnormal $\kappa / \lambda$ ratio $(d, e)$. Results of immunofluorescence staining and in situ zymography with a plasmin-sensitive synthetic substrate for the nephritis-associated plasmin receptor (f) and plasmin activity (g), respectively, are negative. 